Published in final edited form as:

Pharmacol Rep. 2010 ; 62(3): 503-510.

\title{
Transcellular biosynthesis of eicosanoids
}

\author{
Angelo Sala ${ }^{1,2}$, Giancarlo Folco ${ }^{1}$, and Robert C. Murphy ${ }^{2}$ \\ ${ }^{1}$ Department of Pharmacological Sciences, University of Milan, Via Balzaretti 9, 20133 Milano, \\ Italy \\ ${ }^{2}$ Department of Pharmacology, University of Colorado Health Sciences Center, 12800 East 19th \\ Avenue, 80045 Aurora, Colorado, USA
}

\begin{abstract}
The metabolism of arachidonic acid into biologically active compounds involves the sequential activity of a number of enzymes, sometimes showing a unique expression profile in different cells. The main metabolic pathways, namely the cyclooxygenases and the 5-lipoxygenase, both generate chemically unstable intermediates: prostaglandin (PG) $\mathrm{H}_{2}$ and leukotriene (LT) $\mathrm{A}_{4}$, respectively. These are transformed by secondary enzymes into a variety of chemical structures known collectively as the lipid mediators. Although some cells express all the enzymes necessary for the production of biologically active compounds, it has been shown that eicosanoids are often the result of cell-cell interactions involving the transfer of biosynthetic intermediates, such as the chemically reactive $\mathrm{PGH}_{2}$ and leukotriene $\mathrm{LTA}_{4}$, between cells. This process has been defined as the transcellular pathway of eicosanoid biosynthesis and requires both a donor cell to synthesize and release one component of the biosynthetic cascade and an accessory cell to take up that intermediate and process it into the final biologically active product. This review will summarize the evidence for transcellular biosynthetic events, occurring in isolated cell preparations, complex isolated organ systems, and in vivo, that result in the production of prostaglandins, leukotrienes, and lipoxins.
\end{abstract}

\section{Keywords}

inflammatory response; arachidonic acid; prostaglandins; leukotrienes

\section{Introduction}

Eicosanoids are potent mediators known to be involved in a number of physiological and pathophysiological inflammatory responses [20]. Since the discovery of prostaglandins, thromboxanes, lipoxins and leukotrienes as derivatives of arachidonic acid, the efforts to understand the process of their biosynthesis focused on the identification of cells possessing all the specific enzymes necessary for their production, from the release of the arachidonic acid stored in phospholipids to the formation of the final biologically active metabolite and its release into the extracellular milieu. The formation of lipid mediators such as prostaglandins and leukotrienes was therefore believed to be a linear process of events 
taking place in a single cell that had either the complete prostaglandin pathway [membrane phospholipids $\rightarrow$ (cytosolic phospholipase $A_{2}$ ) arachidonic acid $\rightarrow($ cyclooxygenase-1/2) prostaglandin endoperoxides $\rightarrow$ (thromboxane synthase) thromboxane $\mathrm{A}_{2}$ as an example] or the complete leukotriene pathway [membrane phospholipids $\rightarrow$ (cytosolic phospholipase $\left.A_{2}\right)$ arachidonic acid $\rightarrow$ (5-lipoxygenase) leukotriene $\mathrm{A}_{4} \rightarrow$ (leukotriene $A_{4}$ hydrolase) leukotriene $\left.\mathrm{B}_{4}\right]$. Each arrow represents a step that is catalyzed by the specific enzyme in parenthesis. This is the case for platelets or neutrophils that synthesize the pro-aggregating thromboxane $\mathrm{A}_{2}$ and the chemotactic factor leukotriene $\mathrm{B}_{4}$, respectively, using the described "linear" pathways. However, early on it appeared that the environment in which the eicosanoids were biosynthesized played an important role in determining the final production of metabolites. In a seminal article published in 1976 [5], Vane et al. showed that no platelet aggregation was observed when mesenteric artery rings from indomethacin-treated rabbits were incubated with human platelet-rich plasma followed by stimulation of the platelets with ADP. This suggested that the unstable intermediate $\mathrm{PGH}_{2}$ from the platelets was being converted into the antiaggregating $\mathrm{PGI}_{2}$ by the indomethacin-treated arterial rings. It was therefore hypothesized that the production of eicosanoids could be the result of the transfer of a biosynthetic intermediate from a donor cell, possessing a primary oxidative enzyme such as cyclooxygenase or lipoxygenase, to an acceptor cell that, while lacking the ability to produce that intermediate, was nevertheless capable of converting it into biologically active metabolite(s) in the presence of secondary enzymes such as prostaglandin isomerases, $\mathrm{LTA}_{4}$ hydrolase or $\mathrm{LTC}_{4}$ synthases.

This evidence paved the way for the identification of the transcellular biosynthetic pathway of eicosanoid as an important contributor to the final production of prostaglandins, leukotrienes and lipoxins in a number of inflammatory settings. Through the years, evidence related to the occurrence of transcellular metabolic events that lead to eicosanoid biosynthesis has accumulated, ranging from data obtained in simple models of cell-cell coincubations to complex isolated organ preparations and in vivo chimeric animals.

\section{Cell-cell co-incubations}

Following the original evidence Bunting et al. obtained by co-incubating isolated mesenteric vessels and platelet-rich plasma, similar experiments were carried out using purified human umbilical cord endothelial cells (HUVECs) treated with indomethacin. This work showed that endothelial cells were responsible for the uptake and the conversion into $\mathrm{PGI}_{2}$ of platelet-derived $\mathrm{PGH}_{2}$ when incubated in the presence of activated platelet-rich plasma [44]. Direct evidence for the ability of endothelial cells to take up and convert prostaglandin endoperoxide was obtained with the use of radiolabeled $\mathrm{PGH}_{2}$ [28]. Platelet-derived $\mathrm{PGH}_{2}$ was found to be converted into $\mathrm{PGI}_{2}$ when platelets containing radioactive arachidonate were co-incubated with aspirin-treated endothelial cells followed by challenge with various agonists [29].

The transfer of $\mathrm{PGH}_{2}$ from endothelial cells to platelets was also demonstrated using aspirintreated platelets co-incubated with endothelial cells followed by thrombin activation [23]. 
Similar studies were carried out using lymphocyte-HUVEC co-incubations, showing the transfer of lymphocyte-derived $\mathrm{PGH}_{2}$ to endothelial cells illustrated by the formation of endothelial-derived metabolite $\mathrm{PGI}_{2}[31]$.

Evidence for transcellular biosynthesis as a potential mechanisms for eicosanoid production, rather than solely for cyclooxygenase metabolites, was found when Fitzpatrick et al. incubated stabilized $\mathrm{LTA}_{4}$ with red blood cells, showing a significant production of $\mathrm{LTB}_{4}$ [17]. This evidence was also the first to show that a cell incapable of metabolizing arachidonic acid to any extent, due to a lack of cyclooxygenase or any of the lipoxygenases, was nevertheless capable of contributing to the final production of eicosanoids. Shortly thereafter, bone marrow-derived mast cells were found to take up exogenous $\mathrm{LTA}_{4}$, also stabilized by albumin after release from activated neutrophils, and convert it into the sulfidopeptide leukotriene $\mathrm{LTC}_{4}[10]$.

Co-incubations of red blood cells with neutrophils provided the first evidence of different cells cooperating for the synthesis of leukotrienes [30]. The production of $\mathrm{LTB}_{4}$ in the coincubation was significantly higher than that observed upon activation of neutrophils alone. At the same time, $\mathrm{LTC}_{4}$ formation by transcellular biosynthesis was reported by Feinmark and Cannon [16] in co-incubations of endothelial cells and human neutrophils. This work clearly proved the transcellular origin of the $\mathrm{LTC}_{4}$ produced by showing that when intracellular glutathione present in HUVECs was labeled with $\left[{ }^{35} \mathrm{~S}\right]$ cysteine, the production of $\left[{ }^{35} \mathrm{~S}_{\mathrm{LTC}}\right.$ could be observed from neutrophil derived $\mathrm{LTA}_{4}$. Several groups also reported similar results, providing unequivocal evidence that the activation of neutrophils in the presence of endothelial cells could lead to the unexpected formation of cysteinyl leukotrienes [8, 26]. Early on, the neutrophil leukocyte appeared to be a cell type specifically suited to participate in transcellular metabolic processes. It was clearly shown that over $50 \%$ of the $\mathrm{LTA}_{4}$ that resulted from the activation of the 5-lipoxygenase was not metabolized by the cell that synthesized it but was in fact, released into the extracellular milieu [38, 39, 41].

Platelets were also found to be capable of synthesizing $\mathrm{LTC}_{4}$ when incubated with exogenous $\mathrm{LTA}_{4}[13,27]$ or when co-incubated with calcium ionophore-activated neutrophils [27]. Subsequent studies revealed that receptor-mediated activation of neutrophils with fMLP and opsonized zymosan in neutrophil-platelet co-incubations also resulted in $\mathrm{LTC}_{4}$ production directly proportional to the number of platelets in the neutrophil to platelet ratio [25].

The transcellular biosynthesis of leukotrienes has been reported in several other cell-cell coincubations. Kidney-derived, tumor necrosis factor-activiated endothelial cells were found to generate $\mathrm{LTC}_{4}$ when co-incubated with GM-CSF-primed neutrophils followed by challenge with fMLP [4]. Keratinocytes [22] and chondrocytes [2] were also found to metabolize $\mathrm{LTA}_{4}$ into $\mathrm{LTB}_{4}$ and $\mathrm{LTC}_{4}$ when co-incubated with neutrophils, suggesting that these cells also express $\mathrm{LTA}_{4}$ hydrolase and $\mathrm{LTC}_{4}$ synthase. Whereas rat neurons and glial cells do not produce any measurable amount of cysteinyl leukotrienes, when co-cultured with neutrophils, significant production of $\mathrm{LTC}_{4}, \mathrm{LTD}_{4}$ and $\mathrm{LTE}_{4}$ was observed using mass spectrometry [15]. Alveolar macrophages were found to avidly take up exogenous $\mathrm{LTA}_{4}$ and 
generate predominantly $\mathrm{LTB}_{4}$ [19]. The blood peripheral monocyte was also found to be capable of releasing $\mathrm{LTA}_{4}$,providing this reactive intermediate to platelets for transcellular biosynthesis of $\mathrm{LTC}_{4}[3]$.

Lipoxins are a unique case among arachidonic acid metabolites, as these metabolites arise from of the combined action of 12/15-lipoxygenase and 5-lipoxygenase [43]. As a very limited number of cells possess both lipoxygenases, lipoxins represent a typical example of metabolites that result mainly from transcellular metabolism. Indeed, early studies revealed that the calcium ionophore-stimulated neutrophil-platelet co-incubations led to the formation of lipoxin $\mathrm{A}_{4}\left(\mathrm{LXA}_{4}\right)$ that had been derived from neutrophil-generated $\mathrm{LTA}_{4}$ which was transferred to the platelet for conversion into $\mathrm{LXA}_{4}$ by the platelet 12-lipoxygenase [13]. This result is further supported by the observation that $\mathrm{LTA}_{4}$ can be converted into $\mathrm{LXA}_{4}$ by platelets.

More recently, it was observed that when COX-2 was covalently inhibited by acetylation from aspirin, arachidonate was metabolized to 15(R)-HpETE [24, 34], thus making COX-2 behave as a 15(R)-lipoxygenase. Within the framework of lipoxin biosynthesis, 5lipoxygenase and aspirin-treated COX-2 would therefore form lipoxins with the (R) stereochemistry at carbon-15 atom instead of the (S) observed in natural lipoxins. These novel compounds have now been termed "aspirin-triggered lipoxins" (ATLs). As for natural lipoxins, the biosynthesis of ATLs requires donor cells or acceptor cells expressing 5lipoxygenase and the alternative cell type expressing or aspirin-inhibited cyclooxygenase-2 for transcellular biosynthesis. Induced expression of COX-2 by IL-1 followed by aspirin treatment of HUVEC before co-incubation with human neutrophils and stimulation of 5lipoxygenase by the calcium ionophore, led to the production of at least four ATL products that were found to markedly inhibit neutrophil adhesion to endothelial cells [9]. Extensive pharmacological studies have revealed numerous potent anti-inflammatory properties unique to the ATLs [42].

\section{Isolated and perfused organ systems}

Although the experiments carried out using cell-cell co-incubations clearly showed significant production of eicosanoids, it was not possible to evaluate the possible functional effects associated with the formation of biologically active metabolites through the transcellular biosynthetic pathways in these cellular models. In order to overcome this limitation, isolated organ preparations were used as a setting for the cell-cell interaction so that the potential transcellular production of eicosanoid could also be evaluated using functional parameters.

Langendorff preparations of the isolated rabbit heart perfused in a recirculating system with activated human neutrophils were used as a simplified model of cardiac inflammation. The activated neutrophil could adhere to the coronary endothelial cells, providing the optimal conditions for transcellular metabolism to take place. Neutrophils, upon activation with calcium ionophore, were shown to adhere quite avidly to coronary endothelial cells in this model system [37], an event that was associated with rapid formation of $\mathrm{LTC}_{4}$ followed by a delayed increase in coronary perfusion pressure [40]. Both $\mathrm{LTC}_{4}$ production and the 
increase in perfusion pressure were prevented by pretreatment of the neutrophils with the 5lipoxygenase activating-protein inhibitor MK886 $(1 \mu \mathrm{M})$ before adding the neutrophils to the rabbit heart preparation. Similar results were obtained when fMLP $(1 \mu \mathrm{M})$ was used to selectively activate the neutrophil. Interestingly, pretreatment of the neutrophils with a monoclonal antibody directed against the CD-18 subunit of PMN $\beta_{2}$ integrin prior to their addition to the heart preparation resulted in a substantial reduction of cysteinyl leukotriene biosynthesis and virtually no increase in coronary perfusion pressure. These results, along with evidence obtained in cell-cell co-incubations [4], suggest that the adhesion of neutrophils to the endothelial cells may be a prerequisite for transfer of $\mathrm{LTA}_{4}$ from leukocytes to endothelial cells [39].

Recently, the possibility of transcellular biosynthesis taking place in the brain was also examined in a model of isolated perfused guinea pig brain with an intact and functional vascular endothelial barrier [11]. When the brain preparations were infused with human neutrophils that had been primed with GM-CSF ( $1 \mathrm{nM})$ followed by addition of fMLP (100 $\mathrm{nM}$ ) to the infusion buffer, a substantial amount of $\mathrm{LTD}_{4}$ was released into the perfusate as identified by specific mass spectrometric techniques. In addition, there was evidence for the production of $\mathrm{LTB}_{4}$ and non-enzymatic products of $\mathrm{LTA}_{4}$ hydrolysis [11]. These results were consistent with the generation and release of $\mathrm{LTA}_{4}$ by the neutrophils present in the perfusion media and uptake and metabolism of $\mathrm{LTC}_{4}$ by the brain endothelial cells. The formation of cysteinyl leukotrienes was associated with a significant increase in wet brain weight, suggesting edema formation following neutrophil activation. As observed in the rabbit heart preparation [37], the functional effects of the alteration of vascular permeability were prevented by pretreatment of the perfused neutrophils with the inhibitor MK886 or by the dual cys-LT $\mathrm{T}_{1 / 2}$ receptor antagonist Bay u9773 [21], but not the selective cys-LT 1 receptor antagonist, iralukast [6].

\section{In vivo models}

While the reported evidence of transcellular biosynthesis obtained using cell-cell coincubations or isolated organ systems is compelling, the real proof for the potential relevance of this alternative biosynthetic pathway would be to show the occurrence of such events in vivo.

Transcellular biosynthesis of prostaglandins was proposed as an explanation for the results of a study in human subjects where a small skin incision induced a platelet vascular interface known to stimulate both platelets to synthesize $\mathrm{PGH}_{2}$ and $\mathrm{TXA}_{2}$ and endothelial cells to generate $\mathrm{PGH}_{2}$ and, subsequently, $\mathrm{PGI}_{2}$ [32]. Measurements of the production of these active metabolites were performed by sampling the blood leaving the wound site for the hydrolysis products of $\mathrm{TXA}_{2}$ and $\mathrm{PGH}_{2}, \mathrm{TXB}_{2}$ and 6-keto- $\mathrm{PGF}_{1 \mathrm{a}}$, respectively. Results showed that in untreated subjects, the production of $\mathrm{TXB}_{2}$ was quite high, but after treatment with a thromboxane synthase inhibitor, which prevents the conversion of $\mathrm{PGH}_{2}$ into $\mathrm{TXA}_{2}$, the level of $\mathrm{TXB}_{2}$ dropped precipitously, and there was a significant increase in 6-keto-PGF $\mathrm{Pa}_{1 \mathrm{a}}$ and $\mathrm{PGE}_{2}$. These results suggested that in the presence of the thromboxane inhibitor, platelet-derived $\mathrm{PGH}_{2}$ could be diverted into endothelial cells resulting in the transcellular biosynthesis of $\mathrm{PGI}_{2}$ and $\mathrm{PGE}_{2}$. 
In vivo evidence suggesting that the transcellular biosynthesis of cysteinyl leukotrienes occurs in the heart has come from experiments where rabbits underwent to the permanent ligation of the left descending coronary artery. In these studies, the urinary excretion of $\mathrm{LTE}_{4}$ measured $3 \mathrm{~h}$ after ligation showed a significant increase when compared to the concentration of $\mathrm{LTE}_{4}$ observed in the urine of sham-operated animals [39]. Pretreatment of the animals with an anti CD-18 antibody ( $1 \mathrm{mg} / \mathrm{kg} i v)$, which reduces the adhesion and the accumulation of neutrophils into the cardiac tissue, also prevented the elevation of urinary $\mathrm{LTE}_{4}$. This effect was similar to that observed in the isolated rabbit Langendorff preparation perfused with activated neutrophils [39]. It is important to note that in the same in vivo experimental model, pretreatment with the 5-lipoxygenase activating protein inhibitor, BAY X1005, caused significant cardioprotection and reduced mortality. This suggests that inhibition of $\mathrm{LTA}_{4}$ biosynthesis and, ultimately, of transcellular biosynthesis to the cysteinyl leukotrienes played a significant role in the cardiac events [36]. Indeed, the elevation of urinary $\mathrm{LTE}_{4}$ had been reported previously in human subjects with acute myocardial infarctions or unstable angina [7], as well as in human subjects with atherosclerotic coronary artery disease prior to bypass surgery [1]. Although it is very difficult to carry out definitive studies proving or disproving the transcellular biosynthesis hypothesis of cysteinyl leukotrienes in human coronary disease, nonetheless these results are consistent with the formation of $\mathrm{LTE}_{4}$, most likely in a neutrophil-dependent manner. Since neutrophils per se are not synthesizing any measurable amount of cysteinyl leukotrienes, these results are consistent with the transfer of $\mathrm{LTA}_{4}$ from neutrophils to acceptor cells present in the heart, where the final biosynthetic step in the formation of cysteinyl leukotrienes is carried out.

More recently, two separate studies have approached the task of proving the occurrence of transcellular biosynthesis in vivo using a sophisticated approach that involves the development of mice chimeras. In these studies, several chimeric animals have been used: animals in which 5-lipoxygenase is not present (5-LO - /- knockout mice), animals that cannot convert $\mathrm{LTA}_{4}$ into $\mathrm{LTB}_{4}\left(\mathrm{LTA}_{4}\right.$ hydrolase $-/-$ knockout mice) and animals that cannot convert $\mathrm{LTA}_{4}$ into $\mathrm{LTC}_{4}\left(\mathrm{LTC}_{4}\right.$ synthase -/- knockout mice). Lethal irradiation of the 5-LO -/- mice followed by a transplant of the bone marrow from either the $\mathrm{LTA}_{4}$ hydrolase -/- knockout mice [14, 45] or of the $\mathrm{LTC}_{4}$ synthase -/- mice [45], generated animals that did not have any cells expressing 5-LO with the exception of those cells which migrate from the bone marrow through the tissue environment over the course of several weeks. In turn, these 5-LO expressing, bone marrow-derived cells lacked either the $\mathrm{LTC}_{4}$ synthase or the $\mathrm{LTA}_{4}$ hydrolase, enzymes that could only be present in the resident cells of the recipient animal. In these chimeric animals, the biosynthesis of either $\mathrm{LTB}_{4}$ (when the bone marrow used for rescue was from the $\mathrm{LTA}_{4}$ hydrolase knockout animals) or $\mathrm{LTC}_{4}$ (when the bone marrow used for rescue was from the $\mathrm{LTC}_{4}$ synthase knockout animals) could only occur through the transfer of $\mathrm{LTA}_{4}$ from the bone marrow-derived cells (expressing 5-LO) to the resident cells (expressing the secondary biosynthetic enzymes), therefore occurring through transcellular biosynthetic mechanisms (Fig. 1). Zymosan injection into the peritoneal cavity was used to induce an inflammatory response, and leukotrienes, as well as prostaglandins, were isolated from the peritoneal fluid and measured using either enzyme immunoassays [14] or mass spectrometric techniques [45]. These studies unequivocally proved that $\mathrm{LTB}_{4}[14,45]$ and cysteinyl leukotrienes [45] could be 
measured in biologically relevant amounts even when no single cell in a given animal possessed all the enzymes necessary for their synthesis. This provides a clear demonstration that transcellular biosynthesis does indeed take place in vivo. Furthermore, through the evaluation of cell infiltration and permeability alterations, it was possible to determine that the extent of transcellular biosynthesis was at a sufficient level to contribute significantly to the inflammatory response [14].

\section{Conclusions}

Eicosanoids, such as PGs and LTs, are potent lipid mediators involved in inflammatory responses. It is not surprising that their synthesis is tightly regulated through a variety of mechanisms, some of which are not well understood. Transcellular biosynthesis provides a unique way by which the cellular environment may affect the qualitative and quantitative profile of eicosanoids produced. Transcellular biosynthesis also provides added flexibility to biological responses. For example, a chemotactic stimulus can also turn into a vasoactive one by switching from the formation of $\mathrm{LTB}_{4}$ to that of $\mathrm{LTC}_{4}$, while a stimulus for platelet aggregation and vasospasm can concomitantly evoke the formation of vasodilatingantiaggregatory eicosanoids.

The transcellular biosynthesis of eicosanoids can operate under physiological conditions as well as during pathological responses. For example, platelets that are marginalized and have direct contact with the vessel wall, either intact or partly damaged, become activated to synthesize endoperoxides $\left(\mathrm{PGH}_{2}\right)$ that can be converted to antiadhesive vasoprotective agents, such as $\mathrm{PGI}_{2}$, by the neighboring endothelial cells during normal resolution. In pathological conditions, such as during an inflammatory event, marginating leukocytes must undergo the complex processes of diapedesis and tissue infiltration to fulfill their phagocytic duties. In cooperation with the endothelial cells via transcellular biosynthesis mechanisms, leukocytes may switch their production from $\mathrm{LTB}_{4}$ to cysteinyl leukotrienes, promoting the alteration of vascular permeability resulting in the formation of an edema. This represents a fundamental defense mechanism of the body that must become operative when and where needed, but if not properly controlled can clearly lead to tissue damage. Furthermore, transcellular biosynthesis of eicosanoids may represent a common mechanism to switch on (via enhanced production of prostaglandins and leukotrienes) and switch off (via the formation of lipoxins [33]) such complex events.

Transcellular biosynthesis makes it difficult to predict the profile of arachidonate products that will be formed in tissues and organs based on the knowledge of the potential contributions of individual cells. The expression of secondary enzymes in cells that do not possess the primary oxidative enzymes may significantly change the qualitative profile of the eicosanoids produced. While this observation has obvious pathophysiological implications, it is important to emphasize that it may also affect the pharmacological intervention. For example, the presence of infiltrating neutrophils in inflamed tissue might suggest that the use of $\mathrm{LTB}_{4}$ receptor antagonists could control phlogosis, however, if the activated leukocytes contributed $\mathrm{LTA}_{4}$ to acceptor cells (e.g., mast cells) for cysteinyl leukotriene synthesis, cys-LT1 or cys-LT $\mathrm{L}_{2}$ receptor antagonists might be the correct therapeutic intervention. 
The body of evidence presented clearly supports the occurrence of transcellular biosynthesis in vivo, but additional information is needed in order to fully understand the complex picture of the transcellular biosynthetic pathway of eicosanoids. For instance, intermediates, such as $\mathrm{LTA}_{4}$ or $\mathrm{PGH}_{2}$, are extremely labile yet can undergo export from a donor cell, transport to and uptake by the acceptor cell, and finally enzymatic transformation. As the research highlighting the importance of adhesion between donor and acceptor cells pointed out [4, 39], it appears that the transcellular biosynthesis of eicosanoids is facilitated by physical contact between cells. However, there is also evidence that proteins may provide sufficient stabilization of the unstable intermediates to allow transport through the extracellular medium $[12,18,35,46]$. Although little is known about membrane crossing or intra- and extracellular transport of intermediates, each step could indeed represent a target for therapeutic intervention. While the only pharmacological approaches of proven clinical efficacy are the inhibition of the primary oxidative enzymes (cyclooxygenase or lipoxygenase) or antagonism of the cysteine leukotriene receptor, each individual step controlling the final production of eicosanoids, including transcellular mechanisms, could have profound physiopathological implications and may represent a potential pharmacological target.

\section{Acknowledgments}

The authors wish to thank the National Institutes of Health Grant HL025785, the European Community Grant LSHM-CT-2004-005033 and the Fulbright Commission for their support.

\section{Abbreviations}

HUVEC human umbilical cord endothelial cells

LT leukotriene

PG prostaglandin

\section{References}

1. Allen SP, Sampson AP, Piper PJ, Chester AH, Ohri SK, Yacoub MH. Enhanced excretion of urinary leukotriene $\mathrm{E}_{4}$ in coronary artery disease and after coronary artery bypass surgery. Coron Artery Dis. 1993; 4:899-904. [PubMed: 8269196]

2. Amat M, Diaz C, Vila L. Leukotriene $A_{4}$ hydrolase and leukotriene $C_{4}$ synthase activities in human chondrocytes: transcellular biosynthesis of Leukotrienes during granulocyte-chondrocyte interaction. Arthritis Rheum. 1998; 41:1645-1651. [PubMed: 9751098]

3. Bigby TD, Meslier N. Transcellular lipoxygenase metabolism between monocytes and platelets. J Immunol. 1989; 143:1948-1954. [PubMed: 2550547]

4. Brady HR, Serhan CN. Adhesion promotes transcellular leukotriene biosynthesis during neutrophilglomerular endothelial cell interactions: inhibition by antibodies against CD18 and L-selectin. Biochem Biophys Res Commun. 1992; 186:1307-1314. [PubMed: 1380800]

5. Bunting S, Gryglewski R, Moncada S, Vane JR. Arterial walls generate from prostaglandin endoperoxides a substance (prostaglandin $\mathrm{X}$ ) which relaxes strips of mesenteric and coeliac ateries and inhibits platelet aggregation. Prostaglandins. 1976; 12:897-913. [PubMed: 1005741]

6. Capra V, Bolla M, Belloni PA, Mezzetti M, Folco GC, Nicosia S, Rovati GE. Pharmacological characterization of the cysteinyl-leukotriene antagonists CGP 45715A (iralukast) and CGP 57698 in human airways in vitro. Br J Pharmacol. 1998; 123:590-598. [PubMed: 9504401] 
7. Carry M, Korley V, Willerson JT, Weigelt L, Ford-Hutchinson AW, Tagari P. Increased urinary leukotriene excretion in patients with cardiac ischemia. In vivo evidence for 5-lipoxygenase activation. Circulation. 1992; 85:230-236. [PubMed: 1309444]

8. Claesson HE, Haeggstrom J. Human endothelial cells stimulate leukotriene synthesis and convert granulocyte released leukotriene $\mathrm{A}_{4}$ into leukotrienes $\mathrm{B}_{4}, \mathrm{C}_{4}, \mathrm{D}_{4}$ and $\mathrm{E}_{4}$. Eur J Biochem. 1988; 173:93-100. [PubMed: 2833396]

9. Claria J, Serhan CN. Aspirin triggers previously undescribed bioactive eicosanoids by human endothelial cell-leukocyte interactions. Proc Natl Acad Sci USA. 1995; 92:9475-9479. [PubMed: 7568157]

10. Dahinden CA, Clancy RM, Gross M, Chiller JM, Hugli TE. Leukotriene C4 production by murine mast cells: evidence of a role for extracellular leukotriene A4. Proc Natl Acad Sci USA. 1985; 82:6632-6636. [PubMed: 2995976]

11. Di Gennaro A, Carnini C, Buccellati C, Ballerio R, Zarini S, Fumagalli F, Viappiani S, et al. Cysteinyl-leukotrienes receptor activation in brain inflammatory reactions and cerebral edema formation: a role for transcellular biosynthesis of cysteinyl-leukotrienes. Faseb J. 2004; 18:842844. [PubMed: 15001558]

12. Dickinson Zimmer JS, Voelker DR, Bernlohr DA, Murphy RC. Stabilization of leukotriene $\mathrm{A}_{4}$ by epithelial fatty acid-binding protein in the rat basophilic leukemia cell. J Biol Chem. 2004; 279:7420-7426. [PubMed: 14676186]

13. Edenius C, Heidvall K, Lindgren JA. Novel transcellular interaction: conversion of granulocytederived leukotriene $\mathrm{A}_{4}$ to cysteinyl-containing leukotrienes by human platelets. Eur J Biochem. 1988; 178:81-86. [PubMed: 2849545]

14. Fabre JE, Goulet JL, Riche E, Nguyen M, Coggins K, Offenbacher S, Koller BH. Transcellular biosynthesis contributes to the production of leukotrienes during inflammatory responses in vivo. $\mathrm{J}$ Clin Invest. 2002; 109:1373-1380. [PubMed: 12021253]

15. Farias SE, Zarini S, Precht T, Murphy RC, Heidenreich KA. Transcellular biosynthesis of cysteinyl leukotrienes in rat neuronal and glial cells. J Neurochem. 2007; 103:1310-1318. [PubMed: 17711426]

16. Feinmark SJ, Cannon PJ. Endothelial cell leukotriene $\mathrm{C}_{4}$ synthesis results from intercellular transfer of leukotriene $\mathrm{A}_{4}$ synthesized by polymorphonuclear leukocytes. J Biol Chem. 1986; 261:16466-16472. [PubMed: 3023351]

17. Fitzpatrick F, Liggett W, McGee J, Bunting S, Morton D, Samuelsson B. Metabolism of leukotriene $\mathrm{A}_{4}$ by human erythrocytes. A novel cellular source of leukotriene $\mathrm{B}_{4}$. J Biol Chem. 1984; 259:11403-11407. [PubMed: 6088544]

18. Folco G, Granstrom E, Kindahl H. Albumin stabilizes thromboxane A2. FEBS Lett. 1977; 82:321324. [PubMed: 913605]

19. Grimminger F, Sibelius U, Seeger W. Amplification of $\mathrm{LTB}_{4}$ generation in AM-PMN cocultures: transcellular 5-lipoxygenase metabolism. Am J Physiol. 1991; 261:L195-L203. [PubMed: 1651667]

20. Harizi H, Corcuff JB, Gualde N. Arachidonic-acid-derived eicosanoids: roles in biology and immunopathology. Trends Mol Med. 2008; 14:461-469. [PubMed: 18774339]

21. Heise CE, O'Dowd BF, Figueroa DJ, Sawyer N, Nguyen T, Im DS, Stocco R, et al. Characterization of the human cysteinyl leukotriene 2 receptor. J Biol Chem. 2000; 275:3053130536. [PubMed: 10851239]

22. Iversen L, Kristensen P, Gron B, Ziboh VA, Kragballe K. Human epidermis transforms exogenous leukotriene $\mathrm{A}_{4}$ into peptide leukotrienes: possible role in transcellular metabolism. Arch Dermatol Res. 1994; 286:261-266. [PubMed: 7914721]

23. Karim S, Habib A, Levy-Toledano S, Maclouf J. Cyclooxygenase-1 and -2 of endothelial cells utilize exogenous or endogenous arachidonic acid for transcellular production of thromboxane. J Biol Chem. 1996; 271:12042-12048. [PubMed: 8662657]

24. Lecomte M, Laneuville O, Ji C, DeWitt DL, Smith WL. Acetylation of human prostaglandin endoperoxide synthase-2 (cyclooxygenase-2) by aspirin. J Biol Chem. 1994; 269:13207-13215. [PubMed: 8175750] 
25. Maclouf J, Murphy RC, Henson PM. Transcellular biosynthesis of sulfidopeptide leukotrienes during receptor-mediated stimulation of human neutrophil/platelet mixtures. Blood. 1990; 76:1838-1844. [PubMed: 2224131]

26. Maclouf J, Murphy RC, Henson PM. Transcellular sulfidopeptide leukotriene biosynthetic capacity of vascular cells. Blood. 1989; 74:703-707. [PubMed: 2546629]

27. Maclouf JA, Murphy RC. Transcellular metabolism of neutrophil-derived leukotriene $\mathrm{A}_{4}$ by human platelets, A potential cellular source of leukotriene $\mathrm{C}_{4}$. J Biol Chem. 1988; 263:174-181. [PubMed: 2826437]

28. Marcus AJ, Weksler BB, Jaffe EA. Enzymatic conversion of prostaglandin endoperoxide $\mathrm{H}_{2}$ and arachidonic acid to prostacyclin by cultured human endothelial cells. J Biol Chem. 1978; 253:7138-7141. [PubMed: 359543]

29. Marcus AJ, Weksler BB, Jaffe EA, Broekman MJ. Synthesis of prostacyclin from platelet-derived endoperoxides by cultured human endothelial cells. J Clin Invest. 1980; 66:979-986. [PubMed: 6776148]

30. McGee JE, Fitzpatrick FA. Erythrocyte-neutrophil interactions: formation of leukotriene $\mathrm{B}_{4}$ by transcellular biosynthesis. Proc Natl Acad Sci USA. 1986; 83:1349-1353. [PubMed: 3006048]

31. Merhi-Soussi F, Dominguez Z, Macovschi O, Dubois M, Savany A, Lagarde M, Prigent AF. Human lymphocytes stimulate prostacyclin synthesis in human umbilical vein endothelial cells. Involvement of endothelial cPLA2. J Leukoc Biol. 2000; 68:881-889. [PubMed: 11129656]

32. Nowak J, FitzGerald GA. Redirection of prostaglandin endoperoxide metabolism at the plateletvascular interface in man. J Clin Invest. 1989; 83:380-385. [PubMed: 2643628]

33. O'Meara SJ, Rodgers K, Godson C. Lipoxins: update and impact of endogenous pro-resolution lipid mediators. Rev Physiol Biochem Pharmacol. 2008; 160:47-70. [PubMed: 18481030]

34. O'Neill GP, Mancini JA, Kargman S, Yergey J, Kwan MY, Falgueyret JP, Abramovitz M, et al. Overexpression of human prostaglandin $\mathrm{G} / \mathrm{H}$ synthase- 1 and -2 by recombinant vaccinia virus: inhibition by nonsteroidal anti-inflammatory drugs and biosynthesis of 15 -hydroxyeicosatetraenoic acid. Mol Pharmacol. 1994; 45:245-254. [PubMed: 8114674]

35. Rector CL, Murphy RC. Determination of leukotriene $\mathrm{A}_{4}$ stabilization by S100A8/A9 proteins using mass spectrometry. J Lipid Res. 2009; 50:2064-2071. [PubMed: 19269927]

36. Rossoni G, Sala A, Berti F, Testa T, Buccellati C, Molta C, Muller-Peddinghaus R, et al. Myocardial protection by the leukotriene synthesis inhibitor BAY X1005: importance of transcellular biosynthesis of cysteinyl-leukotrienes. J Pharmacol Exp Ther. 1996; 276:335-341. [PubMed: 8558451]

37. Sala A, Aliev GM, Rossoni G, Berti F, Buccellati C, Burnstock G, Folco G, Maclouf J. Morphological and functional changes of coronary vasculature caused by transcellular biosynthesis of sulfidopeptide leukotrienes in isolated heart of rabbit. Blood. 1996; 87:1824-1832. [PubMed: 8634429]

38. Sala A, Bolla M, Zarini S, Muller-Peddinghaus R, Folco G. Release of leukotriene $\mathrm{A}_{4}$ versus leukotriene $\mathrm{B}_{4}$ from human polymorphonuclear leukocytes. J Biol Chem. 1996; 271:1794417948. [PubMed: 8663438]

39. Sala A, Rossoni G, Berti F, Buccellati C, Bonazzi A, Maclouf J, Folco G. Monoclonal anti-CD18 antibody prevents transcellular biosynthesis of cysteinyl leukotrienes in vitro and in vivo and protects against leukotriene-dependent increase in coronary vascular resistance and myocardial stiffness. Circulation. 2000; 101:1436-1440. [PubMed: 10736289]

40. Sala A, Rossoni G, Buccellati C, Berti F, Folco G, Maclouf J. Formation of sulphidopeptideleukotrienes by cell-cell interaction causes coronary vasoconstriction in isolated, cell-perfused heart of rabbit. Br J Pharmacol. 1993; 110:1206-1212. [PubMed: 8298810]

41. Sala A, Testa T, Folco G. Leukotriene $\mathrm{A}_{4}$, and not leukotriene $\mathrm{B}_{4}$, is the main 5-lipoxygenase metabolite released by bovine leukocytes. FEBS Lett. 1996; 388:94-98. [PubMed: 8690098]

42. Serhan CN. Lipoxins and novel aspirin-triggered 15-epi-lipoxins (ATL): a jungle of cell-cell interactions or a therapeutic opportunity? Prostaglandins. 1997; 53:107-137. [PubMed: 9112289]

43. Serhan CN, Samuelsson B. Lipoxins: a new series of eicosanoids (biosynthesis, stereochemistry, and biological activities). Adv Exp Med Biol. 1988; 229:1-14. [PubMed: 3048058] 
44. Weksler BB, Marcus AJ, Jaffe EA. Synthesis of prostaglandin $\mathrm{I}_{2}$ (prostacyclin) by cultured human and bovine endothelial cells. Proc Natl Acad Sci USA. 1977; 74:3922-3926. [PubMed: 333448]

45. Zarini S, Gijon MA, Ransome AE, Murphy RC, Sala A. Transcellular biosynthesis of cysteinyl leukotrienes in vivo during mouse peritoneal inflammation. Proc Natl Acad Sci USA. 2009; 106:8296-8301. [PubMed: 19416808]

46. Zimmer JS, Dyckes DF, Bernlohr DA, Murphy RC. Fatty acid binding proteins stabilize leukotriene $\mathrm{A}_{4}$ : competition with arachidonic acid but not other lipoxygenase products. J Lipid Res. 2004; 45:2138-2144. [PubMed: 15342681] 


\section{Bone Marrow Derived Cells}

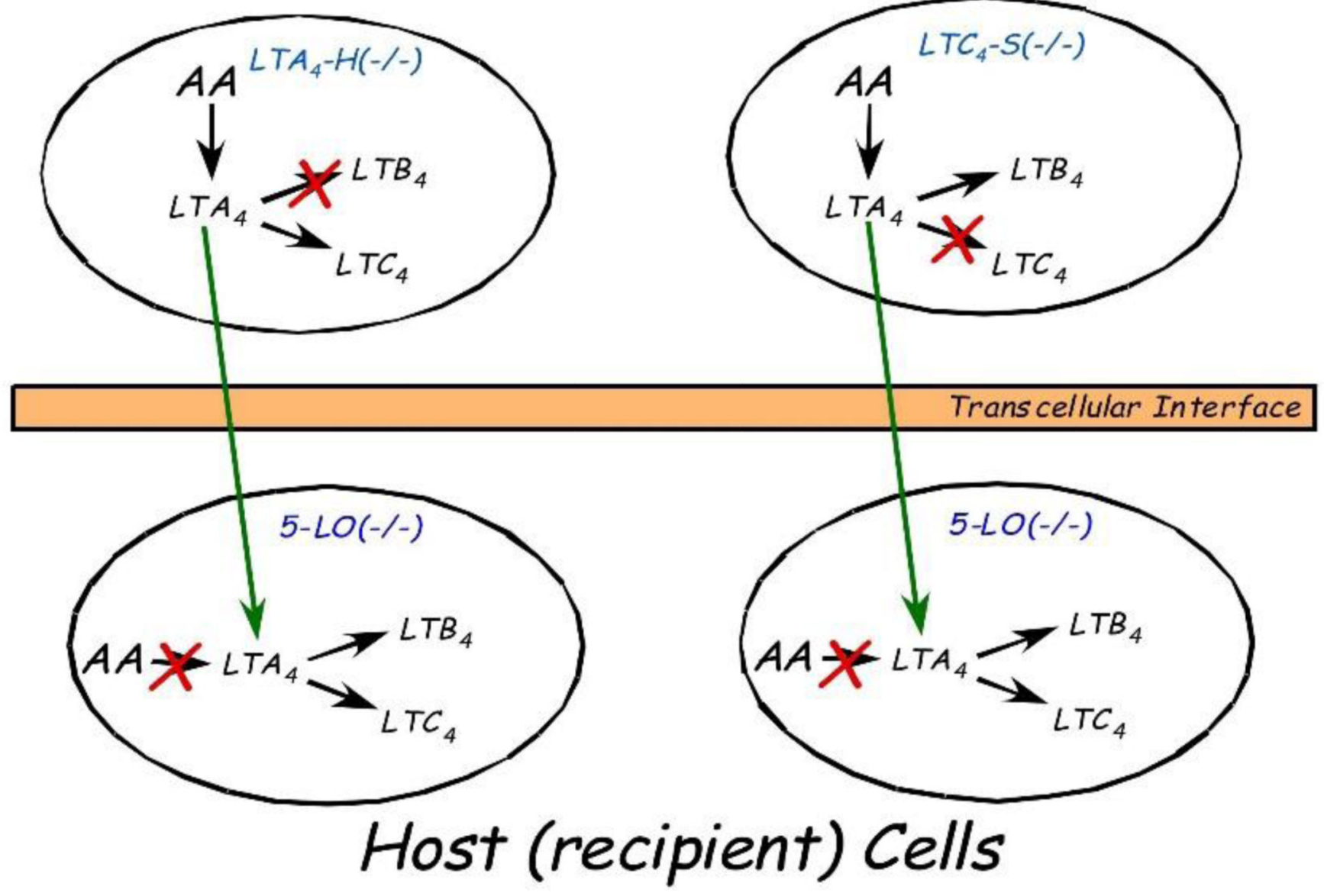

Fig. 1.

Experimental model of leukotriene transcellular biosynthesis. Mice lacking the 5-

lipoxygenase enzyme (5- $\mathrm{LO}-/-)$ were lethally irradiated and rescued with the bone marrow obtained from either $\mathrm{LTA}_{4}$ hydrolase knockout mice $\left(\mathrm{LTA}_{4}-\mathrm{H}-1-\right)$ or $\mathrm{LTC}_{4}$ synthase knockout mice $\left(\mathrm{LTC}_{4} \mathrm{~S}-/-\right)$. In the $\mathrm{LTA}_{4}-\mathrm{H}-/-$ rescue group, no cell in the chimeras will be able to synthesize $\mathrm{LTB}_{4}$, while no cell will be able to synthesize $\mathrm{LTC}_{4}$ when the donor bone marrow originated from the $\mathrm{LTC}_{4} \mathrm{~S}-/-$ animals. Synthesis of $\mathrm{LTB}_{4}$ or $\mathrm{LTC}_{4}$ will only be possible by transcellular metabolism via the transfer of $\mathrm{LTA}_{4}$ from bone marrow derived cells to recipient (host) cells 